Predi ct i ve fact or $s$ for post oper at i ve t achyar $r$ hyt hma af ter thor acoscopi $c$ esophagect omy and the usef ul ness of I andi ol ol hydr ochl ori de for its treat ment

\begin{tabular}{|c|c|}
\hline 著者 & $\begin{array}{l}\text { Okanmt o Koi chi, N nom ya I t asu, Nar uzen Shogo, } \\
\text { Sai to Hi r ot o, Tsukada Tomya, Ki noshi t a Jun, } \\
\text { Naki no I same, Nakamur a Kei shi, Oyama } \\
\text { Kat sunobu, M yashi t a Tomøhar u, Taj i ma } \\
\text { H dehi ro, Takamur a H r oyuki , K t agawa } \\
\text { H r ohi sa, Fushi da Sachi o, Fuj i mur a Takashi, } \\
\text { Oht a Tet suo }\end{array}$ \\
\hline $\begin{array}{l}\text { j our nal or } \\
\text { publ i cat i on title }\end{array}$ & Esophagus \\
\hline vol une & 11 \\
\hline nunber & 2 \\
\hline page $r$ ange & 89-98 \\
\hline year & 20140801 \\
\hline URL & ht t p: //hdl . handl e. net /2297/37574 \\
\hline
\end{tabular}




\title{
Predictive factors for postoperative tachyarrhythmia after thoracoscopic esophagectomy and the usefulness of landiolol hydrochloride for its treatment
}

\author{
Koichi Okamoto $\cdot$ Itasu Ninomiya $\cdot$ Shogo Maruzen $\cdot$ Hiroto Saito $\cdot$ Tomoya Tsukada $\cdot$ Jun Kinoshita \\ Isamu Makino Keishi Nakamura Katsunobu Oyama $\cdot$ Tomoharu Miyashita Hidehiro Tajima • \\ Hiroyuki Takamura $\cdot$ Hirohisa Kitagawa $\cdot$ Sachio Fushida $\cdot$ Takashi Fujimura $\cdot$ Tetsuo Ohta
}

Received: 7 May 2013/Accepted: 25 September 2013/Published online: 16 October 2013

(C) The Japan Esophageal Society and Springer Japan 2013

\begin{abstract}
Background Tachyarrhythmia after esophagectomy is a severe complication that should not be underestimated because of its negative impact. The aims of this study were to clarify the cause and impact of postoperative tachyarrhythmia after thoracoscopic esophagectomy. Additionally, we analyzed the usefulness of landiolol administration for postoperative tachyarrhythmia.

Methods We evaluated the predictive factors for tachyarrhythmia onset after surgery and its clinical impact in 127 patients who underwent thoracoscopic esophagectomy with extended lymphadenectomy. Moreover, we analyzed the efficacy of landiolol for postoperative tachyarrhythmia.

Results Tachyarrhythmia developed in 38 of the 127 patients. Multivariate analysis showed that advanced age, heart disease, and hyperlipidemia were associated with postoperative tachyarrhythmia. Hyponatremia, hypoalbuminemia, and leukocytosis on postoperative day 3 were significantly associated with tachyarrhythmia onset. The incidence of all complications and respiratory complications, including pneumonia, was significantly higher in patients with than in those without tachyarrhythmia. The mortality rate in the tachyarrhythmia group tended to be higher than that in the nontachyarrhythmia group. Landiolol as a treatment for tachyarrhythmia immediately decreased heart rate and safely reduced subsequent respiratory complications.
\end{abstract}

K. Okamoto $(\bowtie) \cdot$ I. Ninomiya $\cdot$ S. Maruzen $\cdot$ H. Saito

T. Tsukada · J. Kinoshita - I. Makino · K. Nakamura

K. Oyama - T. Miyashita - H. Tajima $\cdot$ H. Takamura

H. Kitagawa $\cdot$ S. Fushida $\cdot$ T. Fujimura $\cdot$ T. Ohta

Division of Cancer Medicine, Gastroenterologic Surgery,

Department of Oncology, Graduate School of Medical Science,

Kanazawa University, 13-1 Takara-Machi, Kanazawa,

Ishikawa 920-8641, Japan

e-mail: kookka@coast.ocn.ne.jp
Conclusion In elderly patients with cardiac disease or hyperlipidemia, surgeons should be alert for the occurrence of tachyarrhythmia after esophagectomy. Postoperative tachyarrhythmia is a marker of morbidities with particular emphasis on respiratory complications. However, it can be adequately managed by landiolol, resulting in fewer respiratory complications. Landiolol might be a safe and convenient agent for managing postoperative tachyarrhythmia after thoracoscopic esophagectomy, resulting in lower mortality and morbidity rates.

Keywords Esophageal neoplasm · Tachycardia . Thoracoscopy $\cdot$ Esophagectomy $\cdot$ Landiolol

\section{Introduction}

Tachyarrhythmia is the most common complication after open thoracic surgery $[1,2]$. It has been reported that its occurrence, including atrial fibrillation (AF) and paroxysmal supraventricular tachycardia (PSVT), increases postoperative complications and mortality rates [3-10]. Postoperative tachyarrhythmia is associated with delayed early mobilization, prolonged postoperative hospital stay, and increased medical costs of open thoracic operations [35]. Surgical resection for carcinoma of the esophagus and gastric cardia is still arguably one of the most morbid thoracic operations. Although patient selection and improved postoperative care can significantly decrease hospital mortality rates, the morbidity rate remains high [11-16]. Tachyarrhythmia is among the most frequent complications of esophagectomy [10, 12-14]. Atrial fibrillation after esophagectomy was reported to be a marker for postoperative morbidity and mortality [11-14]. There is a pivotal barrier in establishing the appropriate 
treatment regime against postoperative tachyarrhythmia after esophagectomy.

Although the efficacy of esophagectomy with extended lymphadenectomy remains to be shown in a prospective randomized study, some reports show that better survival can be obtained after extended rather than conventional lymphadenectomy. However, extended lymphadenectomy increases operative morbidity rates, especially those of respiratory complications [17, 18]. Video-assisted thoracoscopic radical esophagectomy (VATS-E) has been developed to reduce the surgical insult. VATS-E minimizes the reduction in vital capacity secondary to chest wall injury and provides survival results comparable with those obtained with open radical esophagectomy [19, 20]. Thoracoscopic esophagectomy has been performed in our institution since 2003. However, in conducting this less-invasive form of surgery, we have often noted postoperative tachyarrhythmia, as occurs in open esophagectomy. Although calcium antagonists or digitalis products have previously been used to treat the condition, we often experienced difficulty controlling heart rate and rhythm in postoperative tachyarrhythmia. Administration of these antitachycardia drugs is reported to induce blood pressure reductions and worsen respiratory status [21]. In recent years, the short-acting $\beta 1$-selective blocker landiolol hydrochloride has been used for treating postoperative tachyarrhythmia after thoracic surgery.

Landiolol has been proposed as being beneficial for managing postoperative tachyarrhythmia after esophagectomy due to its safety, effectiveness on circulatory dynamics and respiratory status, and ease of administration. However, very few case reports about the effectiveness of landiolol hydrochloride for postoperative tachyarrhythmia after esophagectomy have been published [22, 23]. Additionally, clarification of the pathophysiological features of postoperative tachyarrhythmia after esophageal cancer resection and establishment of effective treatments is needed, and no detailed studies about the effectiveness of landiolol for postoperative tachyarrhythmia after thoracoscopic esophagectomy have yet been reported.

In this study, we aimed to identify predictive factors for the onset of postoperative tachyarrhythmia after thoracoscopic esophagectomy analyzed its effect on postoperative clinical course. Moreover, the use of landiolol hydrochloride in managing postoperative tachyarrhythmia after VATS-E was studied in detail.

\section{Methods}

\section{Patients}

Between January 2003 and December 2011, 127 patients with esophageal cancer underwent VATS-E with extensive mediastinal lymphadenectomy at the Department of Gastroenterologic Surgery in Kanazawa University Hospital. Data collected from all patients were reviewed retrospectively. The criteria for VATS-E included the following: no previous radiation therapy, no extensive pleural adhesions, pulmonary function capable of sustaining single-lung ventilation, no concomitant serious medical conditions such as liver cirrhosis, and patient preference for VATS-E. Preoperative assessment included a thorough evaluation of medical history, complete physical examination, standard blood chemistries and counts, and cardiopulmonary evaluation. A history of cardiac disease included at least one of the following: atrial or ventricular arrhythmia, ischemic heart disease, congestive heart failure, or cardiac valve disease. A history of pulmonary disease included emphysema, bronchiectasis, or tuberculosis. As a risk assessment of systemic conditions related to general anesthesia, all patients' conditions were classified based on the American Society of Anesthesiologists (ASA) classification [24]. Each tumor was staged according to the TNM classification of the American Joint Committee on Cancer (AJCC) and the Union Internationale Contre le Cancer (UICC) [25].

Thirty-eight of the 127 (29.9\%) patients who developed postoperative tachyarrhythmia, including AF or PSVT with a heart rate $>120$ beats/min, were placed in the tachyarrhythmia group ( $\mathrm{T}$ group); the remaining 89 patients without tachyarrhythmia were placed in the nontachyarrhythmia group (NT group). The clinicopathological factors and surgical outcomes, including duration of operation, amount of blood loss, amount of intraoperative infusion volume, intraoperative use of blood derivative, and route of reconstruction, were compared between groups. Of the 38 patients with postoperative tachyarrhythmia, 28 were treated with landiolol hydrochloride $(\mathrm{L}$ group) and ten with other medications [nonlandiolol (NL) group]. In all patients, we retrospectively analyzed heart rate, rhythm of heartbeat, systolic $(\mathrm{sBP})$ and diastolic (dBP) blood pressure, saturation of pulse oximetry oxygen $\left(\mathrm{SpO}_{2}\right)$, time of tachyarrhythmia onset, blood test variables, incidence of postoperative complications, and length postoperative hospital stay. Aspiration pneumonia, bronchopneumonia, respiratory failure, and acute respiratory distress syndrome were defined as postoperative respiratory complications. The presence of postoperative complications was defined as grade 2 or greater in accordance with the Clavien-Dindo classification.

Procedure

All patients underwent three-stage esophagectomy and reconstruction. The specific surgical techniques have been described previously [20, 26]. Esophageal mobilization and en bloc mediastinal lymph node dissection were thoroughly 
performed under thoracoscopic observation with the patient in the left lateral position. In particular, the lymph nodes around the bilateral recurrent laryngeal nerves were completely removed, and the nerves were identified and preserved. The bilateral vagus nerve trunk was cut at the caudal side of the bifurcation of the pulmonary branches. We preserved the sympathetic superior cardiac branches as much as possible. Postganglionic fibers from the sympathetic trunk were cut as a result of the dissection. Exenteration of the esophagus and stomach preparation for reconstruction were performed using open laparotomy or hand-assisted laparoscopic surgery with the patient in the supine position. Subsequently, cervical nodes were dissected, and the stomach was anastomozed to the cervical esophagus through the posterior mediastinal or retrosternal route. The basic operative approach was individualized for each patient and governed by tumor location and stage, history of previous abdominal surgery, intraoperative findings, and preoperative comorbid diseases.

\section{Medication}

Tachyarrhythmia was documented by means of electrocardiography, with most patients requiring medical intervention for heart rate and/or rhythm control. For the medical treatment of tachyarrhythmia, calcium-channel antagonists or digitalis products were used before 2007. The short-acting $\beta 1$-selective blocker, landiolol hydrochloride, was approved for use in treating postoperative tachyarrhythmia by Japanese insurance boards in October 2006. Since then, we used landiolol for treating postoperative tachyarrhythmia in 28 patients ( $\mathrm{L}$ group). The remaining ten patients with tachyarrhythmia were in the NL group. The antitachycardia drugs procainamide (one case), atenolol (one case), diltiazem (one case), lanatoside $\mathrm{C}$ (one case), bisoprolol fumarate (one case), and verapamil (two cases) were used with overlapping. In the L group, landiolol was administered in doses of 3-5 $\mu \mathrm{g} / \mathrm{kg} / \mathrm{min}$ after tachyarrhythmia onset at a heart rate $>120$ beats $/ \mathrm{min}$, and the dose was adjusted according to heart rate and rhythm every hour at heart rates $<120$ beats/min. In the five cases since April 2001 that needed continuous landiolol administration for $>24 \mathrm{~h}$, we adjusted the dose with concomitant use of bisoprolol fumarate $2.5-10 \mathrm{mg} /$ day by enteral administration according to heart rate. Profiles of the patients with and without postoperative tachyarrhythmia are shown in Fig. 1.

Statistical analysis

Results are expressed as mean \pm standard deviation (SD). For parametric and nonparametric data, the significance of differences between groups was determined

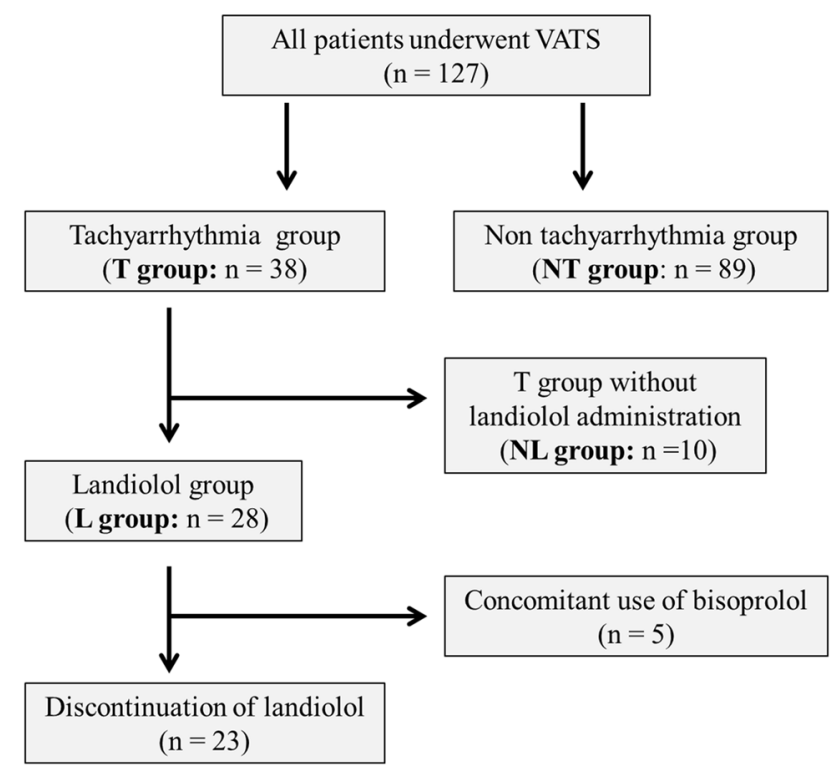

Fig. 1 Profile of patients with and without postoperative tachyarrhythmia in the study. Patients were classified according to tachyarrhythmia occurrence and its treatment strategy

using the Chi-squared test, unpaired Student's $t$ test, or Fisher's exact test, as appropriate. Postoperative parameters of vital signs were compared using two-way analysis of variance (ANOVA). To identify which factors could predict tachyarrhythmia, stepwise multiple logistic regression analysis was used. Values of $P<0.05$ were considered statistically significant. All analyses were done with IBM SPSS (IBM Statistics ver. 19, New York, NY, USA).

\section{Results}

Preoperative characteristics and intraoperative factors of patients with or without postoperative tachyarrhythmia are shown in Table 1 and their preoperative comorbidities are shown in Table 2. Multivariate analysis identified patients $>70$ years old [odds ratio (OR) 2.616, $95 \%$ confidence interval (CI) 1.105-6.195, $P=0.029$ ], a history of cardiac disease (OR 5.189, $95 \%$ CI 1.632-16.50, $P=0.005$ ), and hyperlipidemia (OR 5.189, $95 \%$ CI 1.632-16.50, $P=0.005)$ as independent variables associated with postoperative tachyarrhythmia after VATS-E (Table 3). Twenty-four $(63.2 \%)$ patients with postoperative tachyarrhythmia had at least one of these risk factors. Mean tachyarrhythmia onset time was $57.7 \pm 37.8 \mathrm{~h}$ after surgery in the $\mathrm{T}$ group. Transitions of vital signs in the postoperative course are shown in Fig. 2. A significant increase in the transition of heart rates from postoperative day (POD) 1 to POD 3 was observed in the T group compared wth that in the NT group. Figure 3 shows details of the 
Table 1 Preoperative characteristics and intraoperative factors of patients with and without postoperative tachyarrhythmia

\begin{tabular}{|c|c|c|c|}
\hline & $\begin{array}{l}\text { T group } \\
(n=38)\end{array}$ & $\begin{array}{l}\text { NT group } \\
(n=89)\end{array}$ & $P$ value \\
\hline Age (years) & $67.5 \pm 8.6$ & $64.0 \pm 7.6$ & $0.025^{*}$ \\
\hline Gender $(\mathrm{M} / \mathrm{F})$ & $35 / 3$ & $70 / 19$ & 0.077 \\
\hline $\begin{array}{l}\text { Tumor location: upper, } \\
\text { middle, lower }\end{array}$ & $4,21,13$ & $18,44,27$ & 0.132 \\
\hline Histology (SC, AD, CS, S) & $34,4,0,0$ & $82,4,2,1$ & 0.392 \\
\hline Neoadjuvant chemotherapy & $16(44.7 \%)$ & $28(31.5 \%)$ & 0.309 \\
\hline $\begin{array}{l}\text { Pathological stage (I, II, } \\
\text { III, IV) }\end{array}$ & $12,9,17,0$ & $34,18,36,1$ & 0.781 \\
\hline ASA classification $(1,2,3)$ & $0,30,8$ & $7,75,7$ & $0.030^{*}$ \\
\hline $\begin{array}{l}\text { Route of reconstruction: } \\
\text { mediastinal, retrosternal, } \\
\text { anterior }\end{array}$ & $37,1,0$ & $84,4,1$ & 0.709 \\
\hline Total operation time (min) & $629 \pm 138$ & $620 \pm 126$ & 0.742 \\
\hline $\begin{array}{l}\text { Thoracic operation time } \\
\text { (min) }\end{array}$ & $283 \pm 79$ & $290 \pm 85$ & 0.691 \\
\hline $\begin{array}{l}\text { Total intraoperative blood } \\
\text { loss }(\mathrm{g})\end{array}$ & $679 \pm 671$ & $592 \pm 494$ & 0.417 \\
\hline $\begin{array}{l}\text { Thoracic intraoperative } \\
\text { blood loss }(\mathrm{g})\end{array}$ & $258 \pm 217$ & $253 \pm 180$ & 0.897 \\
\hline $\begin{array}{l}\text { Intraoperative volume of } \\
\text { infusion }(\mathrm{ml})\end{array}$ & $6882 \pm 1676$ & $6676 \pm 1899$ & 0.564 \\
\hline $\begin{array}{l}\text { Intraoperative use of blood } \\
\text { derivative }\end{array}$ & $11(28.9 \%)$ & $20(23.6 \%)$ & 0.500 \\
\hline $\begin{array}{l}\text { Number of dissected } \\
\text { mediastinal lymph nodes }\end{array}$ & $34.1 \pm 14.7$ & $32.8 \pm 12.0$ & 0.611 \\
\hline
\end{tabular}

$T$ tachyarrhythmia, NT nontachyarrhythmia, $E F$ ejection fraction, $S C$ squamous cell carcinoma, $A D$ adenocarcinoma, $S$ small cell carcinoma, CS carcinosarcoma, ASA American Society of Anesthesiologists

$* P<0.05$

transition of the blood test results. The increased incidence of tachyarrhythmia was significantly associated with the following: white blood cell count, low serum albumin level, and low serum sodium concentration on POD 3 ( $P=0.007, P=0.018$, and $P=0.002$, respectively). A comparison of postoperative complications between groups is shown in Table 4. There was a significant difference in the incidence of all postoperative complications between groups (T $76.3 \%$, NT $57.3 \%, P=0.042$ ). The rate of respiratory complications in the $\mathrm{T}$ group was higher than that in the NT group (42.1 vs. $21.3 \%, P=0.017)$. In particular, pneumonia and aspiration were observed more frequently in the $\mathrm{T}$ group (36.8 vs. $16.9 \%, P=0.014$ ). Mortality in the $\mathrm{T}$ group tended to be higher; however, the difference did not reach statistical significance (T $10.7 \%$, NT $0 \%, P=0.08)$. The length of postoperative hospital stay was not different between groups (T $52.7 \pm 40.4$ days, NT $46.3 \pm 28.0$ days, $P=0.310)$.
Table 2 Preoperative comorbidities of patients with and without postoperative tachyarrhythmia

\begin{tabular}{lccc}
\hline & $\begin{array}{l}\text { T group } \\
(n=38)\end{array}$ & $\begin{array}{l}\text { NT group } \\
(n=89)\end{array}$ & $P$ value \\
\hline Age $\geq 70$ years old & $16(42.1 \%)$ & $18(20.2 \%)$ & $0.016^{*}$ \\
Heart disease & $10(26.3 \%)$ & $7(7.9 \%)$ & $0.009^{*}$ \\
Smoking history & $34(89.5 \%)$ & $70(78.7 \%)$ & 0.209 \\
Hypertension & $15(39.5 \%)$ & $24(27.0 \%)$ & 0.208 \\
Diabetes mellitus & $10(26.3 \%)$ & $15(16.9 \%)$ & 0.231 \\
Hyperlipidemia & $8(21.1 \%)$ & $8(9.0 \%)$ & 0.080 \\
Malignancy & $7(18.4 \%)$ & $17(19.1 \%)$ & 1.000 \\
COPD & $7(18.4 \%)$ & $17(19.1 \%)$ & 1.000 \\
Bronchial asthma & $3(7.9 \%)$ & $6(6.7 \%)$ & 1.000 \\
Liver injury & $8(21.1 \%)$ & $11(12.4 \%)$ & 0.277 \\
\hline
\end{tabular}

$T$ tachyarrhythmia, NT nontachyarrhythmia, COPD chronic obstructive pulmonary disease

$* P<0.05$

Table 3 Multivariate analyses of risk factors for postoperative tachyarrhythmia

\begin{tabular}{llll}
\hline Risk factors & Odds ratio & $95 \%$ confidence interval & $P$ value \\
\hline Age $\geq 70$ years & 2.606 & $1.076-6.312$ & $0.029^{*}$ \\
Heart disease & 3.798 & $1.247-11.567$ & $0.019^{*}$ \\
Hyperlipidemia & 3.628 & $1.185-11.112$ & $0.024^{*}$ \\
\hline$P<0.05$ & & &
\end{tabular}

Twenty-eight patients in the $\mathrm{L}$ group underwent continuous low-dose administration of landiolol, with dosage adjusted according to the transition in vital signs. No patient underwent initial rapid injection of landiolol. Landiolol was initially administered at a dosage of $4.1 \pm 2.4 \mu \mathrm{g} / \mathrm{kg} / \mathrm{min}$, and mean administration duration was $110.8 \pm 48.4 \mathrm{~h}$. The remaining ten patients with tachyarrhythmia were in the NL group. Preoperative characteristics, intraoperative factors, and comorbidities of patients with postoperative tachyarrhythmia were not different between groups, as shown in Table 5. The transition of heart rate counts of patients in the $\mathrm{L}$ group is shown in Fig. 4. The mean heart rate of patients in the $\mathrm{L}$ group declined significantly $1 \mathrm{~h}$ after landiolol administration compared with that at onset (onset $143.1 \pm 17.3$ beats $/ \mathrm{min}, 1 \mathrm{~h}$ after start of administration $117.5 \pm 19.6$ beats $/ \mathrm{min}, P<0.01)$. On the other hand, heart rate in NL group patients did not change significantly after medication (onset $131.7 \pm 29.3$ beats $/ \mathrm{min}, 1 \mathrm{~h}$ after medication $110.3 \pm 26.9$ beats $/ \mathrm{min}, P=0.11$ ). The mean time required to decrease the heart rate to $<120$ beats/min after medication in the $\mathrm{L}$ group was significantly shorter than that in the NL group $(\mathrm{L} 4.6 \pm 4.6 \mathrm{~h}, \mathrm{NL} 27.3 \pm 55.0 \mathrm{~h}$, $P=0.033$; Fig. 5). There was no significant difference in 
Fig. 2 Transitions of each vital sign in postoperative course. A significant increase in heart rate was observed between the tachyarrhythmia (T) and nontachyarrhythmia (NT) groups from postoperative day (POD) 1 to POD $3(P=0.003$, $P=0.003$, and $P=0.017$, respectively). $\mathrm{SpO} 2$ saturation of pulse oximetry oxygen, $s B P$ systolic blood pressure, $d B P$ diastolic blood pressure
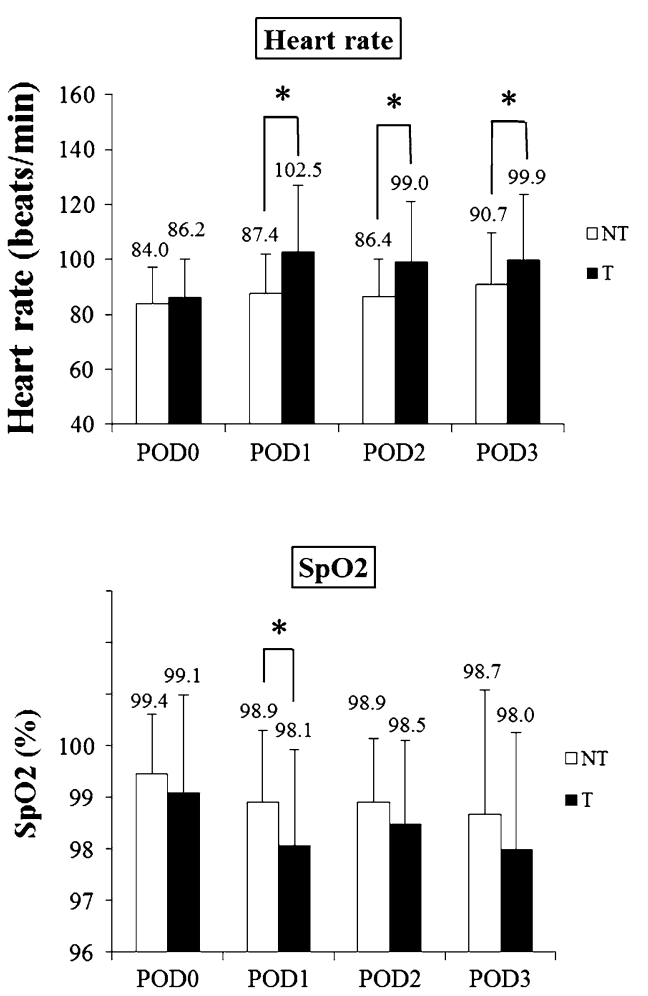
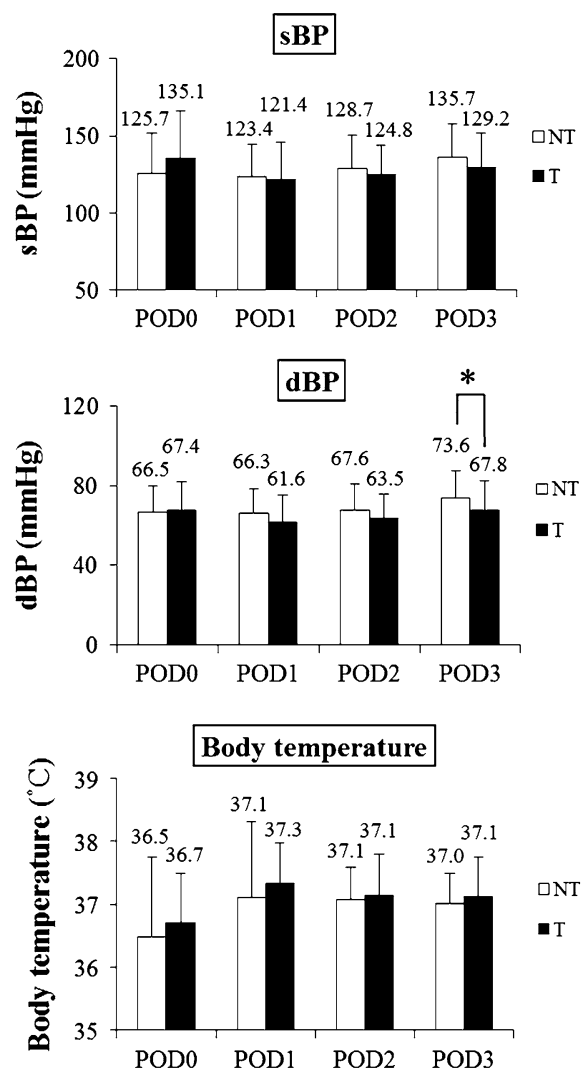
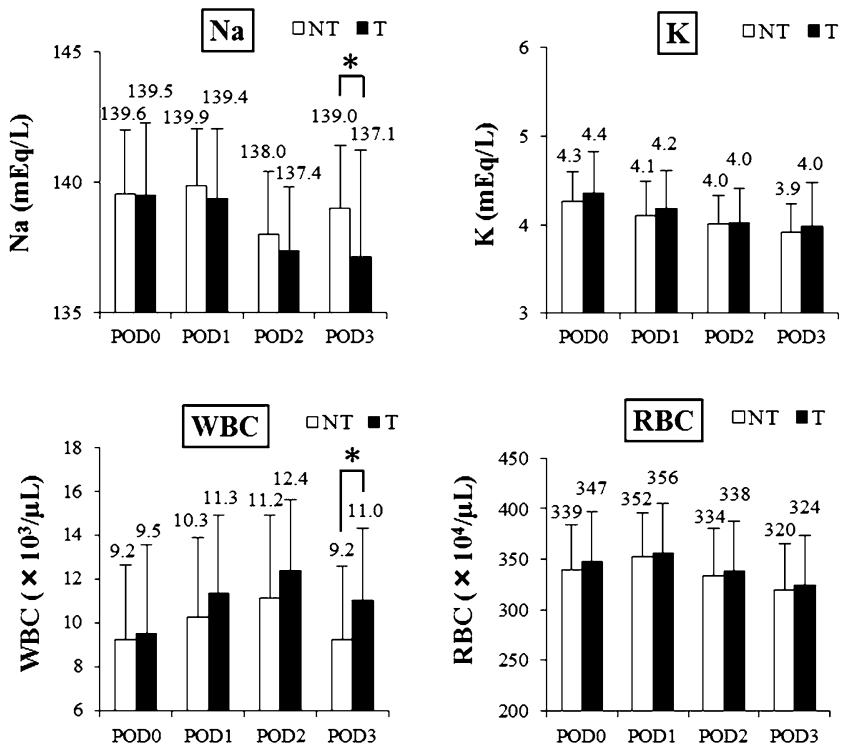

Fig. 3 Transitions of each blood test results in postoperative course. The increased incidence of tachyarrhythmia was significantly associated with a higher white blood cell count, lower serum albumin level, and lower

the time to sinus rhythm conversion between groups ( $\mathrm{L}$ $15.0 \pm 36.7 \mathrm{~h}, \mathrm{NL} 36.9 \pm 55.5 \mathrm{~h}, P=0.176$ ).

Tachyarrhythmia recurred after discontinuation of landiolol administration in three patients in the L group, and landiolol was readministered to these patients. However,
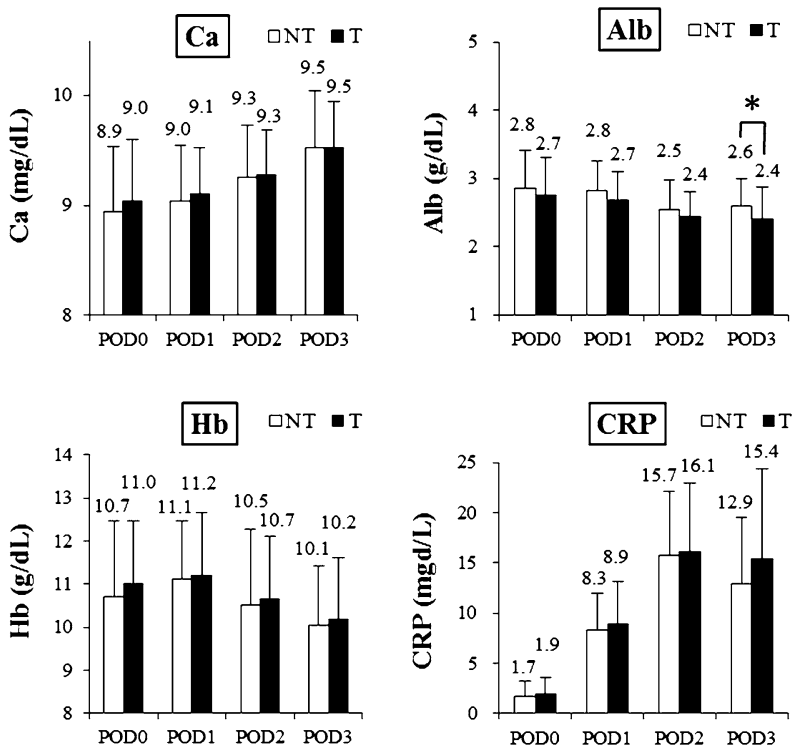

serum sodium concentration on postoperative day (POD) $3(P=0.017$, $P=0.027$, and $P=0.0084$, respectively). $A l b$ albumin, $W B C$ white blood cell, $R B C$ red blood cell, $H b$ hemoglobin, $C R P$ C-reactive protein

tachyarrhythmia recurrence was not seen in five cases with concomitant enteral administration of bisoprolol. No patient converted to chronic AF, except those with complicated chronic AF. There was no significant decline in systolic (sBP) or diastolic (dBP) blood pressure $1 \mathrm{~h}$ after 
Table 4 Postoperative morbidities and length of postoperative hospital stay in patients with and without postoperative tachyarrhythmia

\begin{tabular}{|c|c|c|c|}
\hline & $\begin{array}{l}\text { T group } \\
(n=38)\end{array}$ & $\begin{array}{l}\text { NT group } \\
(n=89)\end{array}$ & $P$ value \\
\hline All complications & $29(76.3 \%)$ & $51(57.3 \%)$ & $0.042 *$ \\
\hline $\begin{array}{l}\text { Respiratory } \\
\text { complications }\end{array}$ & $16(42.1 \%)$ & $19(21.3 \%)$ & $0.017 *$ \\
\hline Pneumonia, aspiration & $14(36.8 \%)$ & $15(16.9 \%)$ & $0.014 *$ \\
\hline $\begin{array}{l}\text { ARDS, respiratory } \\
\text { failure }\end{array}$ & $4(10.5 \%)$ & $4(4.5 \%)$ & 0.239 \\
\hline Recurrent nerve palsy & $15(39.5 \%)$ & $37(41.6 \%)$ & 0.836 \\
\hline $\begin{array}{l}\text { SSI including } \\
\text { anastomotic leakage }\end{array}$ & $8(21.1 \%)$ & $15(16.9 \%)$ & 0.574 \\
\hline Anastomotic leakage & $6(15.8 \%)$ & $8(9.0 \%)$ & 0.353 \\
\hline Heart failure, ACS & $4(10.5 \%)$ & $2(2.2 \%)$ & 0.065 \\
\hline Chylothorax & $5(13.2 \%)$ & $4(4.5 \%)$ & 0.126 \\
\hline Reoperation & $2(5.3 \%)$ & $3(3.4 \%)$ & 0.616 \\
\hline $\begin{array}{l}\text { Length of hospital stay } \\
\text { (days) }\end{array}$ & $52.7 \pm 40.4$ & $46.3 \pm 28.0$ & 0.381 \\
\hline Mortality & $3(7.9 \%)$ & $1(1.1 \%)$ & 0.080 \\
\hline
\end{tabular}

$\overline{T \text { tachyarrhythmia, } N T \text { nontachyarrhythmia, ARDS acute respiratory }}$ distress syndrome, ACS acute coronary syndrome, SSI surgical-site infection

$* P<0.05$

landiolol administration compared with that at the time of onset (sBP onset $117.9 \pm 25.0 \mathrm{mmHg}, 1 \mathrm{~h}$ after administration $114.3 \pm 19.3 \mathrm{mmHg}, P=0.56$; dBP onset $64.8 \pm$ $11.0 \mathrm{mmHg}, 1 \mathrm{~h}$ after administration $63.4 \pm 11.8 \mathrm{mmHg}$, $P=0.63$; Fig. 6). Furthermore, there was no significant decline in mean $\mathrm{SpO}_{2} 1 \mathrm{~h}$ after landiolol administration compared with that at the time of onset (onset $97.8 \pm$ $2.0 \%, 1 \mathrm{~h}$ after administration $98.3 \pm 2.3 \%, P=0.46)$. There was no incidence of asthma attacks after landiolol administration in any patient, including four cases with a history of bronchial asthma.

Postoperative respiratory complications were noted in 19 cases $(21.3 \%)$ in the NT group, nine $(32.1 \%)$ in the L group, and seven $(70 \%)$ in the NL group. The incidence of postoperative respiratory complications did not differ between the NT and L groups (NT vs. L, $P=0.243$ ). The incidence of postoperative respiratory complications in the NL group was significantly higher than those in the NT and L groups (NT vs. NL, $P=0.003$; L vs. NL, $P=0.044)$. There were no significant differences in length of postoperative hospital stay between the NT, L, and NL groups (NT vs. L, $P=0.859 ;$ NT vs. NL, $P=0.401 ; \mathrm{L}$ vs. NL, $P=0.664)$.

\section{Discussion}

We examined the predictive factors for tachyarrhythmia onset after VATS-E and the influence of tachyarrhythmia
Table 5 Preoperative characteristics, comorbidities, and intraoperative factors of patients with postoperative tachyarrhythmia who were administered landiolol (L group) or other medications (NL group)

\begin{tabular}{llll}
\hline & $\begin{array}{l}\text { L group } \\
(n=28)\end{array}$ & $\begin{array}{l}\text { NL group } \\
(n=10)\end{array}$ & $P$ value \\
\hline $\begin{array}{l}\text { Age (years) } \\
\text { Gender (M/F) }\end{array}$ & $67.1 \pm 8.6$ & $68.4 \pm 8.9$ & 0.696 \\
$\begin{array}{l}\text { Neoadjuvant } \\
\text { chemotherapy }\end{array}$ & $14(50 \%)$ & $2(20 \%)$ & 0.143 \\
$\begin{array}{l}\text { Pathological stage (I, II, } \\
\quad \text { III, IV) }\end{array}$ & $9,6,13,0$ & $3,3,4,0$ & 0.768 \\
$\begin{array}{l}\text { ASA classification }(1,2, \\
\quad 3)\end{array}$ & $0,23,5$ & $0,7,3$ & 0.411 \\
$\begin{array}{l}\text { Total operation time } \\
\text { (min) }\end{array}$ & $599 \pm 117$ & $710 \pm 166$ & 0.076 \\
$\begin{array}{l}\text { Thoracic operation time } \\
\text { (min) }\end{array}$ & $274 \pm 74$ & $311 \pm 88$ & 0.257 \\
$\begin{array}{l}\text { Total intraoperative } \\
\text { blood loss (g) }\end{array}$ & $518 \pm 344$ & $1,130 \pm 1,089$ & 0.113 \\
$\begin{array}{l}\text { Thoracic intraoperative } \\
\text { blood loss (g) }\end{array}$ & $243 \pm 216$ & $299 \pm 226$ & 0.503 \\
$\begin{array}{l}\text { Intraoperative volume of } \\
\text { infusion (ml) }\end{array}$ & $6,816 \pm 1,703$ & $7,065 \pm 1,672$ & 0.693 \\
$\begin{array}{l}\text { Intraoperative use of } \\
\text { blood derivative }\end{array}$ & $7(25 \%)$ & $4(40 \%)$ & 0.432 \\
$\begin{array}{l}\text { Number of dissected } \\
\text { mediastinal lymph } \\
\text { nodes }\end{array}$ & $33.8 \pm 15.6$ & $34.9 \pm 12.8$ & 0.832 \\
$\begin{array}{l}\text { Age } \geq 70 \text { years } \\
\begin{array}{l}\text { Heart disease } \\
\text { Hyperlipidemia }\end{array}\end{array}$ & $72(42.9 \%)$ & $4(40 \%)$ & 1.000 \\
\hline ASA Am & $5(21.1 \%)$ & $3(30 \%)$ & 0.411 \\
\hline
\end{tabular}

ASA American Society of Anesthesiologists

$* P<0.05$

in the postoperative clinical course. Our results suggest that advancing age and comorbid heart disease are significant risk factors for postoperative tachyarrhythmia after VATSE. Tachyarrhythmia after VATS-E acts as a surrogate for respiratory complications. In addition, the effectiveness of landiolol hydrochloride for treating tachyarrhythmia was also evaluated. Landiolol immediately decreased the heart rate without any adverse effects and reduced subsequent postoperative morbidities, with particular emphasis on respiratory complications.

There are a few reports on postoperative tachyarrhythmia after open esophagectomy for treating esophageal cancer $[10-14,16]$. The incidence of tachyarrhythmia after conventional open esophagectomy is observed with a high frequency of $12.5-33 \%$ [5, 10, 12-14]. We found frequent postoperative tachyarrhythmia, including AF and PSVT in $38(29.9 \%)$ of 127 patients who underwent VATS-E. The frequency of tachyarrhythmia was consistent with that after conventional open esophagectomy. It has been suggested that thorough mediastinal lymph node dissection is the 


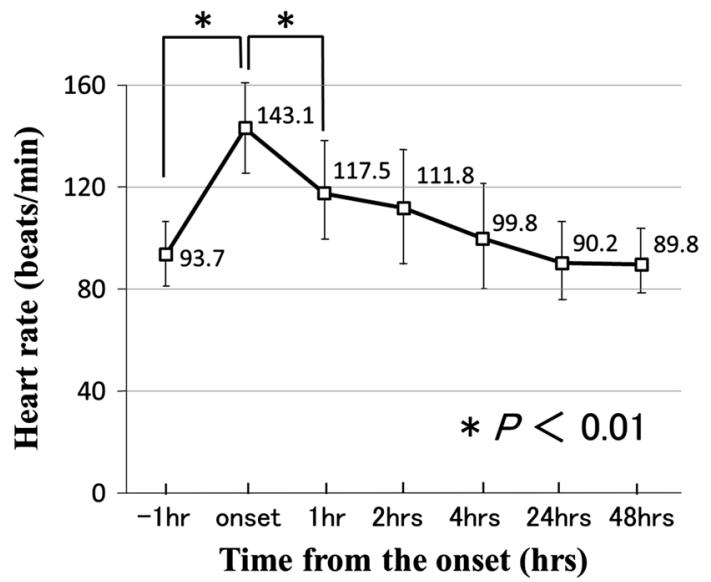

Fig. 4 Changes in heart rate before and after landiolol administration. There is a significant decrease of heart rate counts $1 \mathrm{~h}$ after landiolol administration

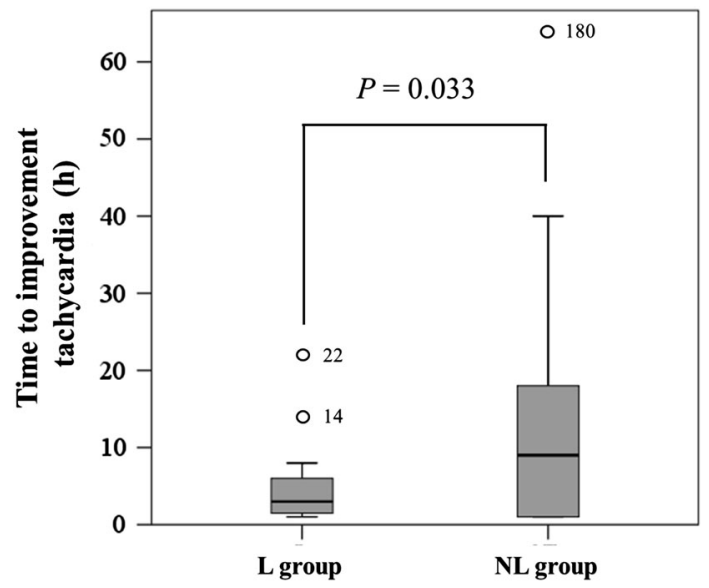

Fig. 5 Mean time to decrease heart rate counts to $\leq 120$ beats/min after medications in the landiolol (L) group was significantly more rapid than in the nonlandiolol (NL) group (L group $4.6 \pm 4.6 \mathrm{~h}$, NL group $27.3 \pm 55.0 \mathrm{~h} ; P=0.033$ )

greatest cause of tachyarrhythmia after esophagectomy. It was concluded that VATS-E may not help reduce the incidence of postoperative tachyarrhythmia. We performed the VATS-E procedure as a curative, extended, mediastinal dissection in the same manner as Osugi et al. [20], who reported comparable survival benefits for VATS-E and open esophagectomy. Autonomous nerve dysfunction caused by local damage to the cardiac branches of the vagus nerve and the sympathetic nerve plexus is thought to be one of the greatest causes of tachyarrhythmia in VATS$\mathrm{E}$, as well as open thoracic surgery. In particular, thorough mediastinal dissection under VATS-E might greatly affect local damage to the mediastinal nerve systems.

Compared with conventionally performed open esophagectomy, VATS-E is recognized as a more beneficial surgical procedure from the viewpoint of suppressing the

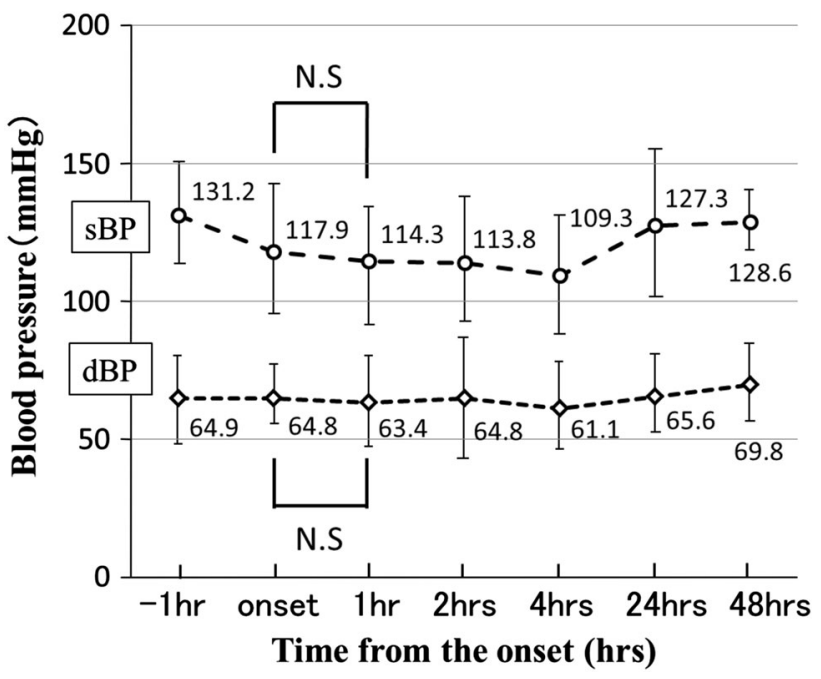

Fig. 6 Changes in systolic (sBP) and diastolic (dBP) blood pressure before and after tachyarrhythmia treatment showed no significant decline

decrease in the amount of ventilation due to chest wall destruction and relief of wound pain. VATS-E was recently recognized as having an oncologic survival benefit comparable with that of open esophagectomy [27]. As a result of the extended dissection procedure under the magnified view, we concluded that the incidence of postoperative tachyarrhythmia does not decrease with VATS-E compared with open esophagectomy. One report showed that patients who underwent extended mediastinal dissection developed tachyarrhythmia more frequently than those who underwent mediastinal dissection restricted to below the level of the tracheal bifurcation, with anastomosis placed in the lower chest [12].

In restricted dissection, vagal nerves cephalad to the inferior pulmonary veins are left largely undisturbed. However, touching the vagus nerve and sympathetic nerves in the upper mediastinum in extended mediastinal dissection cannot be avoided. Although the vagus nerve along the upper part of the trachea is largely preserved after extended mediastinal dissection, some damage to the cardiac branches of the vagus nerve may cause tachyarrhythmia. In addition, postganglionic fibers from the sympathetic trunk are cut as a result of dissection. Preserving cardiac branches of the vagus nerve may be important for reducing the incidence of tachyarrhythmia. Extended lymphadenectomy might also introduce a change in body-fluid balance and electrolyte abnormalities due to leakage of exudate associated with inflammation spreading to the atrium and pulmonary vein. Our study showed that the increased incidence of tachyarrhythmia was associated with leukocytosis, hypoalbuminemia, and hyponatremia. These findings may support the notion that the surgical impact to the mediastinum by extended lymphadenectomy is associated 
with the onset of postoperative tachyarrhythmia after VATS-E.

AF occurs in 10-40\% of pulmonary resection patients and has a peak incidence on the second to third day after surgery [5, 9]. Studies demonstrate that advanced age, male sex, arterial hypertension, ischemic heart disease, heart failure, clamshell incision, and resection of the right lung are significant risk factors for AF after lung surgery, and respiratory and infectious complications are involved in the occurrence of temporally linked AF [7-10]. There are similar reports on postoperative tachyarrhythmia with open esophagectomy [10, 12-14, 16]. The results of our study show that advancing age and heart disease are clear risk factors for developing tachyarrhythmia. Respiratory disease, male sex, expansion of the chest gastric tube, mediastinal lymphadenectomy, and lengthy surgery have been reported as other risk factors after esophagectomy [10, 12, $13,16,18]$. Tachyarrhythmia onset in the late postoperative period was reported to occur more frequently with retrosternal-route reconstruction, but it was independent of immediate postoperative tachyarrhythmia.

The association of postoperative AF with mortality is documented after lung surgery, major noncardiac surgery, and nonthoracic operations [6, 12, 14, 28-30]. Postoperative AF after open esophagectomy is reported to cause a high incidence of postoperative complications, high hospital mortality rate, and increased costs due to prolonged hospital stay. As a result, postoperative AF onset after esophagectomy predicted a worse surgical outcome [1114]. Although intensive care improvements and surgical technique refinements have decreased the postoperative mortality rate after esophagectomy, a striking association between AF and hospital mortality rate was reported [31]. In our study, morbidity rates, including respiratory complications, were significantly higher in patients with tachyarrhythmia ( $\mathrm{T}$ group) than in those without tachyarrhythmia (NT group) after VATS-E. We conclude that postoperative tachyarrhythmia is not merely a systemic manifestation of these serious illnesses and that its onset should be considered as a surrogate for other grave complications. Postoperative tachyarrhythmia did not influence postoperative hospital stay. Mortality in the T group tended to be higher than that in the NT group $(P=0.08)$; however, the difference did not reach statistical significance.

We experienced great difficulty controlling tachyarrhythmia in some cases prior to using landiolol. Uncontrolled tachyarrhythmia can postpone early postoperative ambulation and recovery of a patient's general health. Calcium-channel blockers, $\beta$-blockers, and digitalis preparations for intravenous injection have been used for postoperative tachyarrhythmia, and their effectiveness on heart rate control and return to sinus rhythm is well known. It is also known that $\beta$-blockers and calcium-channel blockers inhibit sympathetic nerves and may adversely affect circulation by causing bradycardia and hypotension [21]. It is also known that $\beta$-blockers tend to induce pulmonary edema and bronchospasm via $\beta 2$-blocking action and may deteriorate the respiratory state. However, landiolol hydrochloride, a short-acting $\beta 1$-selective blocker, is reported to be safe and easy to use because of its high selectivity for the $\beta 1$ receptor (460-670 times greater than propranolol), short half-life of $4 \mathrm{~min}$, low risk for bronchospasms, and because its dose can be easily adjusted. In this study, significant and rapidly decreasing heart-rate counts were observed in L-group patients compared with NL-group patients.

The time to sinus rhythm conversion in the $\mathrm{L}$ group tended to be shorter than that in the NL group. In addition, landiolol pharmacokinetics are only slightly affected by hepatic and renal clearance at a clinical dose [32]. We started to administer landiolol at a low dose at the onset of tachyarrhythmia and adjusted the dose to reduce the heart rate. Neither bradycardia nor a decline in blood pressure was observed as an adverse effect of landiolol, which induced rapid and effective heart-rate control. The majority of L-group cases showed sinus recovery subsequent to tachycardia improvement. Pharmacologically, landiolol has a rate-control effect without an antiarrhythmic effect. Sinus recovery might be an associated effect after rate control.

Landiolol is thought to not cause tracheal spasm. In this study, it was safely administered to patients with asthma (absence of asthma attacks in four patients with a history of bronchial asthma). As a disadvantage, the discontinuation of landiolol administration may cause tachyarrhythmia recurrence due to the absence of its antiarrhythmic effects. To counter this, we changed intravenous administration of landiolol to enteral administration of a $\beta 1$-selective blocker, bisoprolol fumarate, after normal sinus rhythm recovery. The enteral administration of bisoprolol resulted in good long-term heart-rate control.

In recent years, studies on the preventive AF effects of landiolol in coronary surgery have been reported [33-35]. A randomized controlled study shows that AF in cardiac surgery is inhibited by various $\beta$-blockers and that longterm prognosis can be improved with a decrease in complications [35]. In the Guidelines for the Management of Patients with Atrial Fibrillation by the American College of Cardiology/American Heart Association/European Society of Cardiology, prophylactic administration of $\beta$-blockers is recommended after cardiac surgery [36]. Furthermore, Okita et al. [37] report the usefulness of prophylactic intraoperative administration of landiolol in the incidence of AF after lung resection surgery. Nezu et al. [38] report that continuous infusion of low-dose landiolol for 3 days immediately after lung cancer resection effectively 
prevented postoperative tachyarrhythmia. Prophylactic landiolol administration may also effectively prevent tachyarrhythmia after esophageal cancer surgery. Further studies are needed to show the usefulness of prophylactic landiolol administration after esophageal cancer surgery.

As shown in this study, postoperative tachyarrhythmia was a surrogate for subsequent respiratory complications and should be strictly noted. The hospital mortality rate tended to be greater in patients with than in patients without tachyarrhythmia. However, there were no significant differences. Tachyarrhythmia management using landiolol lowered the subsequent respiratory complication rate after tachycardia compared with other management methods. No significant differences were observed in postoperative morbidities and length of postoperative hospital stay between L-group NT-group patients (Table 6). In addition, the incidence of postoperative respiratory complications in L-group patients did not differ between groups. Even if postoperative tachyarrhythmia occurs, landiolol may prevent the occurrence of serious morbidities. The use of landiolol for the majority of patients with tachyarrhythmia showed that it might be beneficial for improving the entire postoperative clinical courses of these patients. Tachyarrhythmia in patients in this study might not have adversely affected postoperative hospital stay and mortality rates as a result of landiolol administration.

Table 6 Postoperative morbidities and the length of postoperative hospital stay in patients with postoperative tachyarrhythmia treated with landiolol (L group) or other medications (NL group)

\begin{tabular}{|c|c|c|c|}
\hline & $\begin{array}{l}\text { L group } \\
(n=28)\end{array}$ & $\begin{array}{l}\text { NL group } \\
(n=10)\end{array}$ & $P$ value \\
\hline All complications & $20(71.4 \%)$ & $9(90 \%)$ & 0.396 \\
\hline $\begin{array}{l}\text { Respiratory } \\
\text { complications }\end{array}$ & $9(32.1 \%)$ & $7(70 \%)$ & $0.044^{*}$ \\
\hline Pneumonia, aspiration & $9(32.1 \%)$ & $5(50 \%)$ & 0.315 \\
\hline $\begin{array}{l}\text { ARDS, respiratory } \\
\text { failure }\end{array}$ & $2(7.1 \%)$ & $2(20 \%)$ & 0.279 \\
\hline Recurrent nerve palsy & $12(42.9 \%)$ & $3(30 \%)$ & 0.709 \\
\hline $\begin{array}{l}\text { SSI including } \\
\text { anastomotic leakage }\end{array}$ & $7(25 \%)$ & $1(10 \%)$ & 0.653 \\
\hline Anastomotic leakage & $5(17.9 \%)$ & $1(10 \%)$ & 1.000 \\
\hline Heart failure, ACS & $3(10.7 \%)$ & $1(10 \%)$ & 1.000 \\
\hline Chylothorax & $3(10.7 \%)$ & $2(20 \%)$ & 0.592 \\
\hline Reoperation & $1(3.6 \%)$ & $1(10 \%)$ & 0.462 \\
\hline $\begin{array}{l}\text { Length of hospital stay } \\
\text { (days) }\end{array}$ & $50.0 \pm 34.1$ & $60.2 \pm 55.9$ & 0.597 \\
\hline Mortality & $3(10.7 \%)$ & $0(0 \%)$ & 0.552 \\
\hline
\end{tabular}

$A R D S$ acute respiratory distress syndrome, SSI surgical-site infection, $A C S$ acute coronary syndrome

$* P<0.05$
In summary, postoperative tachyarrhythmia after VATSE should be strictly noted in patients with advancing age, heart disease, and/or hyperlipidemia. Tachyarrhythmia might be associated with local damage to the mediastinum by extended lymphadenectomy. Landiolol administration may be safe, convenient, and effective for controlling heart rate in patients with postoperative tachyarrhythmia after VATS-E. In addition, the use of landiolol for postoperative tachyarrhythmia might diminish subsequent postoperative respiratory complications. However, special attention should be paid to determine whether postoperative tachyarrhythmia occurs, because landiolol administration might enable treating this underlying life-threatening but potentially treatable complication. Understanding the pathophysiological effect and effective use of antitachycardia drugs is essential, because appropriate tachyarrhythmia treatment may improve esophageal cancer surgery outcomes.

Ethical Statement Our study conforms to the guidelines set forth in the Helsinki Declaration of 1975, as revised in 2000 concerning Human and Animal Rights, and that they followed the policy concerning informed consent. This was a retrospective study performed in accordance with the ethical standards laid down in the Declaration of Helsinki and all subsequent revisions. We protect patient confidentiality and privacy when presenting research results and will not use any information obtained from this study for other purposes.

\section{Conflict of Interest None.}

\section{References}

1. Amar D. Postthoracotomy atrial fibrillation. Curr Opin Anaesthesiol. 2007;20:43-7.

2. Narayan SM, Cain ME, Smith JM. Atrial fibrillation. Lancet. 1997;350:943-50.

3. Mathew JP, Parks R, Savino JS, Friedman AS, Koch C, Mangano DT, et al. Atrial fibrillation following coronary artery bypass graft surgery: predictors, outcomes, and resource utilization. MultiCenter Study of Perioperative Ischemia Research Group. JAMA. 1996;276:300-6.

4. Aranki SF, Shaw DP, Adams DH, Rizzo RJ, Couper GS, VanderVliet M, et al. Predictors of atrial fibrillation after coronary artery surgery. Current trends and impact on hospital resources. Circulation. 1996;94:390-7.

5. De Decker K, Jorens PG, Van Schil P. Cardiac complications after noncardiac thoracic surgery: an evidence-based current review. Ann Thorac Surg. 2003;75:1340-8.

6. von Knorring J, Lepantalo M, Lindgren L, Lindfors O. Cardiac arrhythmias and myocardial ischemia after thoracotomy for lung cancer. Ann Thorac Surg. 1992;53:642-7.

7. Dyszkiewicz W, Skrzypczak M. Atrial fibrillation after surgery of the lung: clinical analysis of risk factors. Eur J Cardiothorac Surg. 1998;13:625-8.

8. Rena O, Papalia E, Oliaro A, Casadio C, Ruffini E, Filosso PL, et al. Supraventricular arrhythmias after resection surgery of the lung. Eur J Cardiothorac Surg. 2001;20:688-93.

9. Curtis JJ, Parker BM, McKenney CA, Wagner-Mann CC, Walls JT, Demmy TL, et al. Incidence and predictors of 
supraventricular dysrhythmias after pulmonary resection. Ann Thorac Surg. 1998;66:1766-71.

10. Vaporciyan AA, Correa AM, Rice DC, Roth JA, Smythe WR, Swisher SG, et al. Risk factors associated with atrial fibrillation after noncardiac thoracic surgery: analysis of 2588 patients. J Thorac Cardiovasc Surg. 2004;127:779-86.

11. Atkins BZ, Shah AS, Hutcheson KA, Mangum JH, Pappas TN, Harpole DH, Jr, et al. Reducing hospital morbidity and mortality following esophagectomy. Ann Thorac Surg. 2004;78:1170-6 (discussion -6).

12. Murthy SC, Law S, Whooley BP, Alexandrou A, Chu KM, Wong J. Atrial fibrillation after esophagectomy is a marker for postoperative morbidity and mortality. J Thorac Cardiovasc Surg. 2003;126:1162-7.

13. Ma JY, Wang Y, Zhao YF, Wu Z, Liu LX, Kou YL, et al. Atrial fibrillation after surgery for esophageal carcinoma: clinical and prognostic significance. World J Gastroenterol. 2006;12:449-52.

14. Stawicki SP, Prosciak MP, Gerlach AT, Bloomston M, Davido HT, Lindsey DE, et al. Atrial fibrillation after esophagectomy: an indicator of postoperative morbidity. Gen Thorac Cardiovasc Surg. 2011;59:399-405.

15. Muller JM, Erasmi H, Stelzner M, Zieren U, Pichlmaier H. Surgical therapy of oesophageal carcinoma. $\mathrm{Br} \mathrm{J}$ Surg. 1990;77:845-57.

16. Bartels H, Stein HJ, Siewert JR. Preoperative risk analysis and postoperative mortality of oesophagectomy for resectable oesophageal cancer. Br J Surg. 1998;85:840-4.

17. Akiyama H, Tsurumaru M, Udagawa H, Kajiyama Y. Radical lymph node dissection for cancer of the thoracic esophagus. Ann Surg. 1994;220:364-72 (discussion 72-3).

18. Fujita H, Kakegawa T, Yamana H, Shima I, Toh Y, Tomita Y, et al. Mortality and morbidity rates, postoperative course, quality of life, and prognosis after extended radical lymphadenectomy for esophageal cancer. Comparison of three-field lymphadenectomy with two-field lymphadenectomy. Ann Surg. 1995;222:654-62.

19. Cuschieri A, Shimi S, Banting S. Endoscopic oesophagectomy through a right thoracoscopic approach. J R Coll Surg Edinb. 1992;37:7-11.

20. Osugi H, Takemura M, Higashino M, Takada N, Lee S, Kinoshita H. A comparison of video-assisted thoracoscopic oesophagectomy and radical lymph node dissection for squamous cell cancer of the oesophagus with open operation. $\mathrm{Br} \mathrm{J}$ Surg. 2003;90:108-13.

21. Mooss AN, Wurdeman RL, Mohiuddin SM, Reyes AP, Sugimoto JT, Scott W, et al. Esmolol versus diltiazem in the treatment of postoperative atrial fibrillation/atrial flutter after open heart surgery. Am Heart J. 2000;140:176-80.

22. Suzuki S, Morimatsu H, Egi M, Shimizu K, Matsusaki T, Sato T, et al. Effect of landiolol on postoperative atrial fibrillation in 7 patients undergoing esophagectomy. J Jpn Soc Intensive Care Med. 2011;18:215-20.

23. Seishima R, Koyanagi K, Nakagawa M, Nagase T, Okabayashi $\mathrm{K}$, Tabuchi $\mathrm{S}$, et al. Usefulness of short-acting $\beta 1$ selective blocker (landiolol hydrochloride) for postoperative tachyarrhythmia after radical operation of esophageal cancer. Jpn J Gastroenterol Surg. 2010;43:990-5.
24. Owens WD, Felts JA, Spitznagel EL Jr. ASA physical status classifications: a study of consistency of ratings. Anesthesiology. 1978:49:239-43.

25. Sobin LH, Gospodarowicz M, Wittekind C. International Union Against Cancer (UICC). TNM Classification of Malignant Tumours, 7th edn. Hoboken: Wiley-Blackwell; 2010.

26. Ninomiya I, Osugi H, Fujimura T, Kayahara M, Takamura H, Takemura M, et al. Results of video-assisted thoracoscopic surgery for esophageal cancer during the induction period. Gen Thorac Cardiovasc Surg. 2008;56:119-25.

27. Watanabe M, Baba Y, Nagai Y, Baba H. Minimally invasive esophagectomy for esophageal cancer: an updated review. Surg Today. 2012;43:237-44.

28. Krowka MJ, Pairolero PC, Trastek VF, Payne WS, Bernatz PE. Cardiac dysrhythmia following pneumonectomy. Clinical correlates and prognostic significance. Chest. 1987;91:490-5.

29. Wahi R, McMurtrey MJ, DeCaro LF, Mountain CF, Ali MK, Smith TL, et al. Determinants of perioperative morbidity and mortality after pneumonectomy. Ann Thorac Surg. 1989;48:33-7.

30. Brathwaite D, Weissman C. The new onset of atrial arrhythmias following major noncardiothoracic surgery is associated with increased mortality. Chest. 1998;114:462-8.

31. Whooley BP, Law S, Murthy SC, Alexandrou A, Wong J. Analysis of reduced death and complication rates after esophageal resection. Ann Surg. 2001;233:338-44.

32. Mio Y. New ultra-short-acting $\beta 1$-blockers: landiolol and esmolol. The Effects on cardiovascular system. Masui. 2006;55:841-8.

33. Tanaka K. Effect of landiolol on hemodynamic improvement and prevention of infusion of atrial fibrillation in the perioperative period of off-pump coronary artery bypass grafting. Kyobu Geka. 2010;63:175-83.

34. Wakamatsu H, Takase S, Sato Y, Seto Y, Kurosawa H, Yokoyama $\mathrm{H}$. Effect of intra-operative low-dose infusion of landiolol hydrochloride on post-operative atrial fibrillation after off-pump coronary artery bypass grafting. Kyobu Geka. 2010;63:764-8.

35. Sezai A, Minami K, Nakai T, Hata M, Yoshitake I, Wakui S, et al. Landiolol hydrochloride for prevention of atrial fibrillation after coronary artery bypass grafting: new evidence from the PASCAL trial. J Thorac Cardiovasc Surg. 2011;141:1478-87.

36. Fuster V, Ryden LE, Cannom DS, Crijns HJ, Curtis AB, Ellenbogen KA, et al. ACC/AHA/ESC 2006 guidelines for the management of patients with atrial fibrillation: full text: a report of the American College of Cardiology/American Heart Association Task Force on practice guidelines and the European Society of Cardiology Committee for Practice Guidelines (Writing Committee to Revise the 2001 guidelines for the management of patients with atrial fibrillation) developed in collaboration with the European Heart Rhythm Association and the Heart Rhythm Society. Europace. 2006;8:651-745.

37. Okita T, Uji M, Shinjo T, Morioka M, Kumano H, Ishimura N, et al. Use of landiolol hydrochloride for the prevention of atrial fibrillation after lung resection. Masui. 2008;57:953-8.

38. Nezu K, Ogawa F, Matsui Y, Amano H, Hara H, Kurouzu N, et al. Effect of postoperative low-dose landiolol hydrochloride for the prevention of tachyarrhythmia after primary lung cancer surgery. Jpn J Chest Surg. 2011;25:472-8. 